Research Article

\title{
Convergence Theorems for a Common Point of Solutions of Equilibrium and Fixed Point of Relatively Nonexpansive Multivalued Mapping Problems
}

\author{
H. Zegeye ${ }^{1}$ and N. Shahzad ${ }^{2}$ \\ ${ }^{1}$ Department of Mathematics, University of Botswana, Private Bag 00704, Gaborone, Botswana \\ ${ }^{2}$ Department of Mathematics, King AbdulAziz University, P.O. Box 80203, Jeddah 21589, Saudi Arabia
}

Correspondence should be addressed to N. Shahzad, nshahzad@kau.edu.sa

Received 14 June 2012; Accepted 25 July 2012

Academic Editor: Yonghong Yao

Copyright (c) 2012 H. Zegeye and N. Shahzad. This is an open access article distributed under the Creative Commons Attribution License, which permits unrestricted use, distribution, and reproduction in any medium, provided the original work is properly cited.

We introduce an iterative process which converges strongly to a common point of set of solutions of equilibrium problem and set of fixed points of finite family of relatively nonexpansive multivalued mappings in Banach spaces.

\section{Introduction}

Let $E$ be a real Banach space with dual $E^{*}$. The function $\phi: E \times E \rightarrow \mathbb{R}^{+}$, defined by

$$
\phi(x, y)=\|x\|^{2}-2\langle x, J y\rangle+\|y\|^{2}, \quad \text { for } x, y \in E,
$$

is studied by Alber [1] and Reich [2], where $J$ is the normalized duality mapping from $E$ to $2^{E^{*}}$ defined by $J x:=\left\{f^{*} \in E^{*}:\left\langle x, f^{*}\right\rangle=\|x\|^{2}=\left\|f^{*}\right\|^{2}\right\}$, where $\langle\cdot, \cdot\rangle$ denotes the generalized duality pairing. It is well known that $E$ is smooth if and only if $J$ is single valued and if $E$ is uniformly smooth then $J$ is uniformly continuous on bounded subsets of $E$. We note that in a Hilbert space $H, J$ is the identity operator.

Let $C$ be a nonempty closed convex subset of a Hilbert space $H$. It is well known that the metric projection of $H$ onto $C, P_{C}: H \rightarrow C$, is nonexpansive. This fact actually characterizes Hilbert spaces and consequently, it is not available in more general Banach spaces. In 
this direction, Alber [1] introduced a generalized projection operator $\Pi_{C}$ in a Banach space $E$ which is an analogue of metric projection in Hilbert spaces.

Let $C$ be a nonempty closed and convex subset of a reflexive, strictly convex and smooth Banach space E. The generalized projection mapping, introduced by Alber [1], is a mapping $\Pi_{C}: E \rightarrow C$, that assigns to an arbitrary point $x \in E$ the minimum point of the functional $\phi(y, x)$, that is, $\Pi_{C} x=\bar{x}$, where $\bar{x}$ is the solution to the minimization problem

$$
\phi(\bar{x}, x)=\min \{\phi(y, x), y \in C\}
$$

Let $C$ be a nonempty closed convex subset of a Banach space $E$. Let $T: C \rightarrow C$ be a singlevalued mapping. An element $p \in C$ is called a fixed point of $T$ if $T(p)=p$. The set of fixed points of $T$ is denoted by $F(T)$. A point $p$ in $C$ is said to be an asymptotic fixed point of $T$ (see [2]) if $C$ contains a sequence $\left\{x_{n}\right\}$ which converges weakly to $p$ such that $\lim _{n \rightarrow \infty}\left\|x_{n}-T x_{n}\right\|=0$. The set of asymptotic fixed points of $T$ will be denoted by $\widehat{F}(T)$. T is said to be nonexpansive if $\|T x-T y\| \leq\|x-y\|$ for each $x, y \in C$ and is called relatively nonexpansive if (A1) $F(T) \neq \emptyset$; (A2) $\phi(p, T x) \leq \phi(p, x)$ for $x \in C$ and $p \in F(T)$ and (A3) $F(T)=\widehat{F}(T)$.

Let $C$ be a nonempty closed convex subset of a Banach space $E$ and let $N(C)$ and $C B(C)$ denote the family of nonempty subsets and nonempty closed bounded subsets of $C$, respectively. Let $H$ be the Hausdorff metric on $C B(C)$ defined by

$$
H(A, B)=\max \left\{\sup _{a \in A} d(a, B), \sup _{b \in B} d(b, A)\right\}
$$

for all $A, B \in C B(C)$, where $d(a, B)=\inf \{\|a-b\|: b \in B\}$ is the distance from the point $a$ to the subset $B$.

Let $T: C \rightarrow C B(C)$ be a multivalued mapping. $T$ is said to be a nonexpansive if $H(T x, T y) \leq\|x-y\|$, for $x, y \in C$. An element $p \in C$ is called a fixed point of $T$, if $p \in F(T)$, where $F(T):=\{p \in C: p \in T(p)\}$. A point $p \in C$ called an asymptotic fixed point of $T$, if there exists a sequence $\left\{x_{n}\right\}$ in $C$ which converges weakly to $p$ such that $\lim _{n \rightarrow \infty} d\left(x_{n}, T x_{n}\right)=0 . T$ is said to be relatively nonexpansive if (B1) $F(T) \neq \emptyset$; (B2) $\phi(p, u) \leq \phi(p, x)$ for $x \in C, u \in T x$, $p \in F(T)$ and (B3) $F(T)=\widehat{F}(T)$, where $\widehat{F}(T)$ is the set of asymptotic fixed points of $T$.

We remark that the class of relatively nonexpansive single-valued mappings is contained in a class of relatively nonexpansive multi-valued mappings. An example of relatively nonexpansive multi-valued mapping by Homaeipour and Razani [3] is given below.

Example 1.1. Let $I=[0,1], X=L^{p}(I), 1<p<\infty$ and $C=\{f \in X: f(x) \geq 0$, for all $x \in I\}$. Let $T: C \rightarrow C B(C)$ be defined by

$$
T(f)= \begin{cases}\left\{g \in C: f(x)-\frac{3}{4} \leq g(x) \leq f(x)-\frac{1}{4}, \forall x \in I\right\}, & \text { if } f(x)>1, x \in I \\ \{0\}, & \text { otherwise. }\end{cases}
$$

It is shown in [3] that $T$ is relatively nonexpansive multi-valued mapping which is not nonexpansive. 
The study of fixed points for multi-valued nonexpansive mappings in relation to Hausdorff metric was introduced by Markin [4] (see also [5]). Since then a lot of activity in this area and fixed point theory for multi-valued nonexpansive mappings has been developed which has some nontrivial applications in pure and applied sciences including control theory, convex optimization, differential inclusion, and economics (see, e.g., [6] and references therein). Later, Lim [7] established the existence of fixed points for multi-valued nonexpansive mappings in uniformly convex Banach spaces.

It is well known that the normal Mann's iterative [8] algorithm has only weak convergence in an infinite-dimensional Hilbert space even for nonexpansive single-valued mappings. Consequently, in order to obtain strong convergence, one has to modify the normal Mann's iteration algorithm, the so called hybrid projection iteration method is such a modification. The hybrid projection iteration algorithm (HPIA) was introduced initially by Haugazeau [9] in 1968. For 40 years, (HPIA) has received rapid developments. For details, the readers are referred to papers [10-12] and the references therein.

In 2003, Nakajo and Takahashi [12] proposed the following modification of the Mann iteration method for a nonexpansive single-valued mapping $T$ in a Hilbert space $H$ :

$$
\begin{gathered}
x_{0} \in C, \text { chosen arbitrary, } \\
y_{n}=\alpha_{n} x_{n}+\left(1-\alpha_{n}\right) T x_{n}, \\
C_{n}=\left\{z \in C:\left\|y_{n}-z\right\| \leq\left\|x_{n}-z\right\|\right\}, \\
Q_{n}=\left\{z \in C:\left\langle x_{n}-z, x_{0}-x_{n}\right\rangle \geq 0\right\}, \\
x_{n+1}=P_{C_{n} \cap Q_{n}}\left(x_{0}\right), \quad n \geq 0,
\end{gathered}
$$

where $C$ is a closed convex subset of $H, P_{C}$ denotes the metric projection from $H$ onto $C$. They proved that if the sequence $\left\{\alpha_{n}\right\}$ is bounded above from one then the sequence $\left\{x_{n}\right\}$ generated by (1.5) converges strongly to $P_{F(T)}\left(x_{0}\right)$.

In spaces more general than Hilbert spaces, Matsushita and Takahashi [11] proposed the following hybrid iteration method with generalized projection for relatively nonexpansive single-valued mapping $T$ in a Banach space $E$ :

$$
\begin{gathered}
x_{0} \in C, \text { chosen arbitrary, } \\
y_{n}=J^{-1}\left(\alpha_{n} J x_{n}+\left(1-\alpha_{n}\right) J T x_{n}\right), \\
C_{n}=\left\{z \in C: \phi\left(z, y_{n}\right) \leq \phi\left(z, x_{n}\right)\right\}, \\
Q_{n}=\left\{z \in C:\left\langle x_{n}-z, J x_{0}-J x_{n}\right\rangle \geq 0\right\}, \\
x_{n+1}=\prod_{C_{n} \cap Q_{n}}\left(x_{0}\right), \quad n \geq 0 .
\end{gathered}
$$

They proved the following convergence theorem.

Theorem MT. Let E be a uniformly convex and uniformly smooth Banach space, let $C$ be a nonempty closed convex subset of $E$, let $T$ be a relatively nonexpansive single-valued mapping from $C$ into itself, and let $\left\{\alpha_{n}\right\}$ be a sequence of real numbers such that $0 \leq \alpha_{n}<1$ and $\limsup _{n \rightarrow \infty} \alpha_{n}<1$. 
Suppose that $\left\{x_{n}\right\}$ is given by (1.6), where $J$ is the duality mapping on E. If $F(T)$ is nonempty, then $\left\{x_{n}\right\}$ converges strongly to $\Pi_{F(T)} x_{0}$, where $\Pi_{F(T)}(\cdot)$ is the generalized projection from $E$ onto $F(T)$.

Let $f: C \times C \rightarrow \mathbb{R}$ be a bifunction, where $\mathbb{R}$ is the set of real numbers. The equilibrium problem for $f$ is

$$
\text { finding } x^{*} \in C \text { such that } f\left(x^{*}, y\right) \geq 0, \quad \forall y \in C \text {. }
$$

The solution set of (1.7) is denoted by $E P(f)$.

If $f(x, y)=\langle A x, y-x\rangle$, where $A: C \rightarrow C$ is a monotone mapping, then the problem (1.7) reduces to the system of variational inequality problem

$$
\text { find an element } x^{*} \in C \quad \text { such that }\left\langle A x^{*}, y-x^{*}\right\rangle \geq 0, \quad \forall y \in C \text {. }
$$

That is, the problem (1.8) is a special case of (1.7). The set of solutions of inequality (1.8) is denoted by $\operatorname{VI}(C, A)$.

For solving the equilibrium problem for a bifunction $f: C \times C \rightarrow R$, we assume that $f$ satisfies the following conditions:

(A1) $f(x, x)=0$, for all $x \in C$,

(A2) $f$ is monotone, that is, $f(x, y)+f(y, x) \leq 0$, for all $x, y \in C$,

(A3) for each $x, y, z \in C, \lim _{t \rightarrow 0^{+}} f(t z+(1-t) x, y) \leq f(x, y)$,

(A4) for each $x \in C, y \rightarrow f(x, y)$ is convex and lower semicontinuous.

Recently, many authors studied the problem of finding a common element of the set of fixed points of nonexpansive or relatively nonexpansive single-valued mapping and the set of solutions of an equilibrium problems in the frame work of Hilbert spaces and Banach spaces, respectively: see, for instance, $[2,13-21]$ and the references therein.

In [22], Kumam introduced the following iterative scheme in a Hilbert space:

$$
\begin{gathered}
x_{0} \in H, \\
u_{n} \in C \text { such that } f\left(u_{n}, y\right)+\frac{1}{r_{n}}\left\langle y-u_{n}, u_{n}-y_{n}\right\rangle \geq 0, \quad \forall y \in C, \\
w_{n}=\alpha_{n} x_{n}+\left(1-\alpha_{n}\right) T u_{n}, \\
C_{n}=\left\{z \in H:\left\|w_{n}-z\right\| \leq\left\|x_{n}-z\right\|\right\}, \\
Q_{n}=\left\{z \in C:\left\langle x_{n}-z, x_{0}-x_{n}\right\rangle \geq 0\right\}, \\
x_{n+1}=P_{C_{n+1} \cap Q_{n}}\left(x_{0}\right), \quad n \geq 0,
\end{gathered}
$$

for finding a common element of the set of fixed point of nonexpansive single-valued mapping $T$ and set of solution of equilibrium problems. 
In the case that $E$ is a Banach space, Takahashi and Zembayashi [16] introduced the following iterative scheme which is called the shrinking projection method:

$$
\begin{gathered}
x_{0} \in C, \quad \text { chosen arbitrary, } \\
y_{n}=J^{-1}\left(\alpha_{n} J x_{n}+\left(1-\alpha_{n}\right) J T x_{n}\right), \\
u_{n} \in C \text { such that } f\left(u_{n}, y\right)+\frac{1}{r_{n}}\left\langle y-u_{n}, J u_{n}-J y_{n}\right\rangle \geq 0, \quad \forall y \in C, \\
C_{n+1}=\left\{z \in C_{n}: \phi\left(z, u_{n}\right) \leq \phi\left(z, x_{n}\right)\right\}, \\
x_{n+1}=\prod_{C_{n+1}}\left(x_{0}\right), \quad n \geq 0,
\end{gathered}
$$

where $J$ is the duality mapping on $E, \Pi_{C}$ is the generalized projection from $E$ onto $C$ and $T$ is relatively nonexpansive single-valued mapping. They proved that the sequence $\left\{x_{n}\right\}$ converges strongly to a common element of the set of fixed point of relatively nonexpansive single-valued mapping and set of solution of equilibrium problem under appropriate conditions.

We remark that the computation of $x_{n+1}$ in (1.9) and (1.10) is not simple because of the involvement of computation of $C_{n+1}$ from $C_{n}$ for each $n \geq 0$.

More recently, Homaeipour and Razani [3] studied the following iterative scheme for a fixed point of relatively nonexpansive multi-valued mapping in uniformly convex and uniformly smooth Banach space $E$ :

$$
\begin{gathered}
x_{0} \in C, \quad \text { chosen arbitrary, } \\
x_{n+1}=\Pi_{C} J^{-1}\left(\alpha_{n} J x_{n}+\left(1-\alpha_{n}\right) J z_{n}\right), \quad z_{n} \in T x_{n}, n \geq 0,
\end{gathered}
$$

where $\left\{\alpha_{n}\right\} \subset(0,1)$ for all $n \geq 0$ and $\liminf _{n \rightarrow \infty} \alpha_{n}\left(1-\alpha_{n}\right)>0$. They proved that if $J$ is weakly sequentially continuous then the sequence $\left\{x_{n}\right\}$ converges weakly to a fixed point of $T$. Furthermore, it is shown that the scheme converges strongly to a fixed point of $T$ if interior of $F(T)$ is nonempty.

But it is worth mentioning that the convergence of the scheme is either weak or it requires that the interior of $F(T)$ is nonempty.

In this paper, motivated by Kumam [22], Takahashi and Zembayashi [16], and Homaeipour and Razani [3], we construct an iterative scheme which converges strongly to a common point of set of solutions of equilibrium problem and set of fixed points of finite family of relatively nonexpansive multi-valued mappings in Banach spaces. Our scheme does not involve computation of $C_{n}$ and $Q_{n}$, for each $n \geq 0$, and the requirement that the interior of $F$ is nonempty is dispensed with. Our theorems improve and unify most of the results that have been proved for this important class of nonlinear operators. 


\section{Preliminaries}

Let $E$ be a normed linear space with $\operatorname{dim} E \geq 2$. The modulus of smoothness of $E$ is the function $\rho_{E}:[0, \infty) \rightarrow[0, \infty)$ defined by

$$
\rho_{E}(\tau):=\sup \left\{\frac{\|x+y\|+\|x-y\|}{2}-1:\|x\|=1 ;\|y\|=\tau\right\} .
$$

The space $E$ is said to be smooth if $\rho_{E}(\tau)>0$, for all $\tau>0$ and $E$ is called uniformly smooth if and only if $\lim _{t \rightarrow 0^{+}}\left(\rho_{E}(t) / t\right)=0$.

The modulus of convexity of $E$ is the function $\delta_{E}:(0,2] \rightarrow[0,1]$ defined by

$$
\delta_{E}(\epsilon):=\inf \left\{1-\left\|\frac{x+y}{2}\right\|:\|x\|=\|y\|=1 ; \epsilon=\|x-y\|\right\} .
$$

$E$ is called uniformly convex if and only if $\delta_{E}(\epsilon)>0$, for every $\epsilon \in(0,2]$.

In the sequel, we will need the following results.

Lemma 2.1 (see [1]). Let $K$ be a nonempty closed and convex subset of a real reflexive, strictly convex, and smooth Banach space $E$ and let $x \in E$. Then for all $y \in K$,

$$
\phi\left(y, \Pi_{K} x\right)+\phi\left(\Pi_{K} x, x\right) \leq \phi(y, x) .
$$

We make use of the function $V: E \times E^{*} \rightarrow \mathbb{R}$, defined by

$$
V\left(x, x^{*}\right)=\|x\|^{2}-2\left\langle x, x^{*}\right\rangle+\left\|x^{*}\right\|^{2}, \quad \forall x \in E, x^{*} \in E^{*},
$$

studied by Alber [1]. That is, $V\left(x, x^{*}\right)=\phi\left(x, J^{-1} x^{*}\right)$ for all $x \in E$ and $x^{*} \in E^{*}$. We know the following lemma.

Lemma 2.2 (see [1]). Let E be reflexive strictly convex and smooth Banach space with $E^{*}$ as its dual. Then

$$
V\left(x, x^{*}\right)+2\left\langle J^{-1} x^{*}-x, y^{*}\right\rangle \leq V\left(x, x^{*}+y^{*}\right),
$$

for all $x \in E$ and $x^{*}, y^{*} \in E^{*}$.

Lemma 2.3 (see [1]). Let $C$ be a convex subset of a real smooth Banach space E. Let $x \in E$. Then $x_{0}=\Pi_{C} x$ if and only if

$$
\left\langle z-x_{0}, J x-J x_{0}\right\rangle \leq 0, \quad \forall z \in C .
$$


Lemma 2.4 (see [23]). Let E be a uniformly convex Banach space and $B_{R}(0)$ be a closed ball of $E$. Then, there exists a continuous strictly increasing convex function $g:[0, \infty) \rightarrow[0, \infty)$ with $g(0)=0$ such that

$$
\left\|\alpha_{1} x_{1}+\alpha_{2} x_{2}+\cdots+\alpha_{N} x_{N}\right\|^{2} \leq \sum_{i=1}^{N} \alpha_{i}\left\|x_{i}\right\|^{2}-\alpha_{i} \alpha_{j} g\left(\left\|x_{i}-x_{j}\right\|\right)
$$

for $i, j \in\{1, \ldots, N\}, \alpha_{i} \in(0,1)$ such that $\sum_{i=1}^{N} \alpha_{i}=1$, and $x_{i} \in B_{R}(0):=\{x \in E:\|x\| \leq R\}$, for $i=1,2, \ldots, N$.

Lemma 2.5 (see [24]). Let $E$ be a real smooth and uniformly convex Banach space and let $\left\{x_{n}\right\}$ and $\left\{y_{n}\right\}$ be two sequences of $E$. If either $\left\{x_{n}\right\}$ or $\left\{y_{n}\right\}$ is bounded and $\phi\left(x_{n}, y_{n}\right) \rightarrow 0$ as $n \rightarrow \infty$, then $x_{n}-y_{n} \rightarrow 0$, as $n \rightarrow \infty$.

Proposition 2.6 (see [3]). Let $E$ be a strictly convex and smooth Banach space and $C$ be a nonempty closed convex subset of $E$. Let $T: C \rightarrow N(C)$ be a relatively nonexpansive multi-valued mapping. Then $F(T)$ is closed and convex.

Lemma 2.7 (see [16]). Let $C$ be a nonempty, closed and convex subset of a uniformly smooth, strictly convex and reflexive real Banach space $E$. Let $f$ be a bifunction from $C \times C$ to $\mathbb{R}$ which satisfies conditions (A1)-(A4). For $r>0$ and $x \in E$, define the mapping $F_{r}: E \rightarrow C$ as follows:

$$
F_{r} x:=\left\{z \in C: f(z, y)+\frac{1}{r}\langle y-z, J z-J x\rangle \geq 0, \forall y \in C\right\} .
$$

Then the following statements hold:

(1) $F_{r}$ is single-valued,

(2) $F\left(F_{r}\right)=E P(f)$,

(3) $\phi\left(q, F_{r} x\right)+\phi\left(F_{r} x, x\right) \leq \phi(q, x)$, for $q \in F\left(F_{r}\right)$,

(4) $E P(f)$ is closed and convex.

Lemma 2.8 (see [25]). Let $\left\{a_{n}\right\}$ be sequences of real numbers such that there exists a subsequence $\left\{n_{i}\right\}$ of $\{n\}$ such that $a_{n_{i}}<a_{n_{i}+1}$ for all $i \in \mathbb{N}$. Then there exists a nondecreasing sequence $\left\{m_{k}\right\} \subset \mathbb{N}$ such that $m_{k} \rightarrow \infty$ and the following properties are satisfied by all (sufficiently large) numbers $k \in \mathbb{N}$ :

$$
a_{m_{k}} \leq a_{m_{k}+1}, \quad a_{k} \leq a_{m_{k}+1}
$$

In fact, $m_{k}=\max \left\{j \leq k: a_{j}<a_{j+1}\right\}$.

Lemma 2.9 (see [26]). Let $\left\{a_{n}\right\}$ be a sequence of nonnegative real numbers satisfying the following relation:

$$
a_{n+1} \leq\left(1-\beta_{n}\right) a_{n}+\beta_{n} \delta_{n}, \quad n \geq n_{0}, \text { for some } n_{0} \in \mathbb{N},
$$

where $\left\{\beta_{n}\right\} \subset(0,1)$ and $\left\{\delta_{n}\right\} \subset R$ satisfying the following conditions: $\lim _{n \rightarrow \infty} \beta_{n}=0, \sum_{n=1}^{\infty} \beta_{n}=\infty$, and $\lim \sup _{n \rightarrow \infty} \delta_{n} \leq 0$. Then, $\lim _{n \rightarrow \infty} a_{n}=0$. 


\section{Main Result}

Let $C$ be a nonempty, closed and convex subset of a smooth, strictly convex and reflexive real Banach space $E$ with dual $E^{*}$. Let $f: C \times C \rightarrow \mathbb{R}$ be a bifunction. For the rest of this paper, $F_{r_{n}} x$ is a mapping defined as follows. For $x \in E$, let $F_{r_{n}}: E \rightarrow C$ be given by

$$
F_{r_{n}} x:=\left\{z \in C: f(z, y)+\frac{1}{r_{n}}\langle y-z, J z-J x\rangle \geq 0, \forall y \in C\right\}
$$

where $\left\{r_{n}\right\}_{n \in \mathbb{N}} \subset\left[c_{1}, \infty\right)$, for some $c_{1}>0$.

Theorem 3.1. Let $C$ be a nonempty, closed and convex subset of a uniformly smooth and uniformly convex real Banach space E. Let $f: C \times C \rightarrow \mathbb{R}$, be a bifunction which satisfies conditions (A1)-(A4). Let $T_{i}: C \rightarrow C B(C)$, for $i=1,2, \ldots, N$, be a finite family of relatively nonexpansive multi-valued mappings. Assume that $F:=\cap_{i=1}^{N} F\left(T_{i}\right) \cap E P(f)$ is nonempty. Let $\left\{x_{n}\right\}$ be a sequence generated by

$$
\begin{gathered}
x_{0}=w \in C, \quad \text { chosen arbitrarily, } \\
w_{n}=F_{r_{n}} x_{n}, \\
y_{n}=\Pi_{C} J^{-1}\left(\alpha_{n} J w+\left(1-\alpha_{n}\right) J w_{n}\right), \\
x_{n+1}=J^{-1}\left(\beta_{n, 0} J w_{n}+\sum_{i=1}^{N} \beta_{n, i} J u_{n, i}\right), \quad u_{n, i} \in T_{i} y_{n}, n \geq 0,
\end{gathered}
$$

where $\alpha_{n} \in(0,1)$ such that $\lim _{n \rightarrow \infty} \alpha_{n}=0, \sum_{n=1}^{\infty} \alpha_{n}=\infty,\left\{\beta_{n, i}\right\} \subset[a, b] \subset(0,1)$, for $i=1,2, \ldots, N$, satisfying $\beta_{n, 0}+\beta_{n, 1}+\cdots+\beta_{n, N}=1$, for each $n \geq 0$. Then $\left\{x_{n}\right\}$ converges strongly to an element of $F$.

Proof. Since $F$ is nonempty closed and convex, put $x^{*}:=\Pi_{F} w$. Now from (3.2), Lemma 2.7(3) and property of $\phi$, we get that

$$
\begin{aligned}
\phi\left(x^{*}, y_{n}\right)= & \phi\left(x^{*}, \Pi_{C} J^{-1}\left(\alpha_{n} J w+\left(1-\alpha_{n}\right) J w_{n}\right)\right) \\
\leq & \phi\left(x^{*}, J^{-1}\left(\alpha_{n} J w+\left(1-\alpha_{n}\right) J w_{n}\right)\right) \\
= & \left\|x^{*}\right\|^{2}-2\left\langle x^{*}, \alpha_{n} J w+\left(1-\alpha_{n}\right) J w_{n}\right\rangle+\left\|\alpha_{n} J w+\left(1-\alpha_{n}\right) J w_{n}\right\|^{2} \\
\leq & \left\|x^{*}\right\|^{2}-2 \alpha_{n}\left\langle x^{*}, J w\right\rangle-2\left(1-\alpha_{n}\right)\left\langle x^{*}, J w_{n}\right\rangle \\
& +\alpha_{n}\|w\|^{2}+\left(1-\alpha_{n}\right)\left\|w_{n}\right\|^{2} \\
\leq & \alpha_{n} \phi\left(x^{*}, w\right)+\left(1-\alpha_{n}\right) \phi\left(x^{*}, w_{n}\right) \\
= & \alpha_{n} \phi\left(x^{*}, w\right)+\left(1-\alpha_{n}\right) \phi\left(x^{*}, F_{r_{n}} x_{n}\right) \\
\leq & \alpha_{n} \phi\left(x^{*}, w\right)+\left(1-\alpha_{n}\right) \phi\left(x^{*}, x_{n}\right) .
\end{aligned}
$$


Now, from (3.2), Lemma 2.7(3), relatively nonexpansiveness of $T_{i}$, property of $\phi$ and (3.3), we have that

$$
\begin{aligned}
\phi\left(x^{*}, x_{n+1}\right) & =\phi\left(x^{*}, J^{-1}\left(\beta_{n, 0} J w_{n}+\sum_{i=1}^{N} \beta_{n, i} J u_{n, i}\right)\right) \\
& \leq \beta_{n, 0} \phi\left(x^{*}, w_{n}\right)+\sum_{i=1}^{N} \beta_{n, i} \phi\left(x^{*}, u_{n, i}\right) \\
& =\beta_{n, 0} \phi\left(x^{*}, F_{r_{n}} x_{n}\right)+\sum_{i=1}^{N} \beta_{n, i} \phi\left(x^{*}, u_{n, i}\right) \\
& \leq \beta_{n, 0} \phi\left(x^{*}, x_{n}\right)+\left(1-\beta_{n, 0}\right) \phi\left(x^{*}, y_{n}\right) \\
& \leq \beta_{n, 0} \phi\left(x^{*}, x_{n}\right)+\left(1-\beta_{n, 0}\right)\left[\alpha_{n} \phi\left(x^{*}, w\right)+\left(1-\alpha_{n}\right) \phi\left(x^{*}, x_{n}\right)\right] \\
& \leq \delta_{n} \phi\left(x^{*}, w\right)+\left(1-\delta_{n}\right) \phi\left(x^{*}, x_{n}\right),
\end{aligned}
$$

where $\delta_{n}=\left(1-\beta_{n, 0}\right) \alpha_{n}$. Thus, by induction,

$$
\phi\left(x^{*}, x_{n+1}\right) \leq \max \left\{\phi\left(x^{*}, x_{0}\right), \phi\left(x^{*}, w\right)\right\}, \quad \forall n \geq 0,
$$

which implies that $\left\{x_{n}\right\}$ is bounded and hence $\left\{y_{n}\right\}$ and $\left\{w_{n}\right\}$ are bounded. Now let $z_{n}=$ $J^{-1}\left(\alpha_{n} J w+\left(1-\alpha_{n}\right) J w_{n}\right)$. Then we have that $y_{n}=\Pi_{C} z_{n}$. Using Lemma 2.2 and property of $\phi$, we obtain that

$$
\begin{aligned}
\phi\left(x^{*}, y_{n}\right) & \leq \phi\left(x^{*}, z_{n}\right)=V\left(x^{*}, J z_{n}\right) \\
& \leq V\left(x^{*}, J z_{n}-\alpha_{n}\left(J w-J x^{*}\right)\right)-2\left\langle z_{n}-x^{*},-\alpha_{n}\left(J w-J x^{*}\right)\right\rangle \\
& =\phi\left(x^{*}, J^{-1}\left(\alpha_{n} J x^{*}+\left(1-\alpha_{n}\right) J w_{n}\right)+2 \alpha_{n}\left\langle z_{n}-x^{*}, J w-J x^{*}\right\rangle\right) \\
& \leq \alpha_{n} \phi\left(x^{*}, x^{*}\right)+\left(1-\alpha_{n}\right) \phi\left(x^{*}, w_{n}\right)+2 \alpha_{n}\left\langle z_{n}-x^{*}, J w-J x^{*}\right\rangle \\
& =\left(1-\alpha_{n}\right) \phi\left(x^{*}, w_{n}\right)+2 \alpha_{n}\left\langle z_{n}-x^{*}, J w-J x^{*}\right\rangle \\
& \leq\left(1-\alpha_{n}\right) \phi\left(x^{*}, x_{n}\right)+2 \alpha_{n}\left\langle z_{n}-x^{*}, J w-J x^{*}\right\rangle .
\end{aligned}
$$


Furthermore, from (3.2), Lemma 2.4, relatively nonexpansiveness of $T_{i}$, for each $i=$ $1,2, \ldots, N$, Lemma $2.7(3)$, and (3.6) we have that

$$
\begin{aligned}
\phi\left(x^{*}, x_{n+1}\right)= & \phi\left(x^{*}, J^{-1}\left(\beta_{n, 0} J w_{n}+\sum_{i=1}^{N} \beta_{n, i} J u_{n, i}\right)\right) \\
\leq & \beta_{n, 0} \phi\left(x^{*}, w_{n}\right)+\sum_{i=1}^{N} \beta_{n, i} \phi\left(x^{*}, u_{n, i}\right) \\
& -\beta_{n, 0} \beta_{n, i} g\left(\left\|J w_{n}-J u_{n, i}\right\|\right) \\
= & \beta_{n, 0} \phi\left(x^{*}, F_{r_{n}} x_{n}\right)+\sum_{i=1}^{N} \beta_{n, i} \phi\left(x^{*}, u_{n, i}\right) \\
& -\beta_{n, 0} \beta_{n, i} g\left(\left\|J w_{n}-J u_{n, i}\right\|\right) \\
\leq & \beta_{n, 0}\left(\phi\left(x^{*}, x_{n}\right)-\phi\left(x_{n}, w_{n}\right)\right)+\left(1-\beta_{n, 0}\right) \phi\left(x^{*}, y_{n}\right) \\
& -\beta_{n, 0} \beta_{n, i} g\left(\left\|J w_{n}-J u_{n, i}\right\|\right) \leq \beta_{n, 0} \phi\left(x^{*}, x_{n}\right)-\beta_{n, 0} \phi\left(x_{n}, w_{n}\right)+\left(1-\beta_{n, 0}\right) \\
& \times\left[\left(1-\alpha_{n}\right) \phi\left(x^{*}, x_{n}\right)+2 \alpha_{n}\left\langle z_{n}-x^{*}, J w-J x^{*}\right\rangle\right]-\beta_{n, 0} \beta_{n, i} g\left(\left\|J w_{n}-J u_{n, i}\right\|\right) \\
= & \left(1-\delta_{n}\right) \phi\left(x^{*}, x_{n}\right)+2 \delta_{n}\left\langle z_{n}-x^{*}, J w-J x^{*}\right\rangle \\
& -\beta_{n, 0} \phi\left(x_{n}, w_{n}\right)-\beta_{n, 0} \beta_{n, i} g\left(\left\|J w_{n}-J u_{n, i}\right\|\right),
\end{aligned}
$$

and hence

$$
\phi\left(x^{*}, x_{n+1}\right) \leq\left(1-\delta_{n}\right) \phi\left(x^{*}, x_{n}\right)+2 \delta_{n}\left\langle z_{n}-x^{*}, J w-J x^{*}\right\rangle,
$$

where $\delta_{n}:=\alpha_{n}\left(1-\beta_{n, 0}\right)$, for all $n \in \mathbb{N}$. Note that $\delta_{n}$ satisfies $\lim _{n} \delta_{n}=0$ and $\sum_{n=1}^{\infty} \delta_{n}=\infty$.

Now, we consider two cases.

Case 1. Suppose that there exists $n_{0} \in \mathbb{N}$ such that $\left\{\phi\left(x^{*}, x_{n}\right)\right\}$ is nonincreasing for all $n \geq n_{0}$. In this situation, $\left\{\phi\left(x^{*}, x_{n}\right)\right\}$ is then convergent. Then from (3.7), we have that $\phi\left(x_{n}, w_{n}\right) \rightarrow 0$ and hence Lemma 2.5 implies that

$$
x_{n}-w_{n} \longrightarrow 0, \quad \text { as } n \longrightarrow \infty
$$

Moreover, from (3.7), we have that $\beta_{n, 0} \beta_{n, i} g\left(\left\|J w_{n}-J u_{n, i}\right\|\right) \rightarrow 0$, as $n \rightarrow \infty$, which implies by the property of $g$ that $J w_{n}-J u_{n, i} \rightarrow 0$, as $n \rightarrow \infty$, for each $i \in\{1,2, \ldots, N\}$, and hence, since $J^{-1}$ uniformly continuous on bounded sets, we obtain that

$$
w_{n}-u_{n, i} \longrightarrow 0, \quad \text { as } n \longrightarrow \infty
$$


Furthermore, by Lemma 2.1, property of $\phi$ and the fact that $\alpha_{n} \rightarrow 0$, as $n \rightarrow \infty$, imply that

$$
\begin{aligned}
\phi\left(w_{n}, y_{n}\right) & =\phi\left(w_{n}, \Pi_{C} z_{n}\right) \leq \phi\left(w_{n}, z_{n}\right) \\
& =\phi\left(w_{n}, J^{-1}\left(\alpha_{n} J w+\left(1-\alpha_{n}\right) J w_{n}\right)\right) \\
& \leq \alpha_{n} \phi\left(w_{n}, w\right)+\left(1-\alpha_{n}\right) \phi\left(w_{n}, w_{n}\right) \longrightarrow 0, \text { as } n \longrightarrow \infty,
\end{aligned}
$$

and hence

$$
w_{n}-y_{n} \longrightarrow 0, \quad w_{n}-z_{n} \longrightarrow 0, \quad \text { as } n \longrightarrow \infty
$$

Therefore, from (3.9), (3.10), and (3.12), we obtain that

$$
\begin{gathered}
x_{n}-z_{n} \longrightarrow 0, \quad y_{n}-x_{n} \longrightarrow 0, \quad \text { as } n \longrightarrow \infty, \\
d\left(y_{n}, T_{i} y_{n}\right) \leq\left\|y_{n}-u_{n, i}\right\| \leq\left\|y_{n}-w_{n}\right\|+\left\|w_{n}-u_{n, i}\right\| \longrightarrow 0,
\end{gathered}
$$

as $n \rightarrow \infty$, for each $i \in\{1,2, \ldots, N\}$.

Let $\left\{z_{n_{i}}\right\}$ be a subsequence of $\left\{z_{n}\right\}$ such that $z_{n_{i}} \rightarrow z$ and $\lim \sup _{n \rightarrow \infty}\left\langle z_{n}-x^{*}, J w-\right.$ $\left.J x^{*}\right\rangle=\lim _{i \rightarrow \infty}\left\langle z_{n_{i}}-x^{*}, J w-J x^{*}\right\rangle$. Then, from (3.12), (3.13), and the uniform continuity of $J$, we get that

$$
x_{n_{i}}, w_{n_{i}}, y_{n_{i}}-z, \quad J x_{n}-J w_{n} \longrightarrow 0, \quad \text { as } n \longrightarrow \infty
$$

Now, we show that $z \in E P(f)$. But, from the definition of $w_{n}$ and (A2) we note that

$$
\frac{1}{r_{n_{i}}}\left\langle y-w_{n_{i}}, J w_{n_{i}}-J x_{n_{i}}\right\rangle \geq-f\left(w_{n_{i}}, y\right) \geq f\left(y, w_{n_{i}}\right), \quad \forall y \in C
$$

Letting $i \rightarrow \infty$, we have from (3.15) and (A4) that $f(y, z) \leq 0$, for all $y \in C$. Now, for $0<t \leq 1$ and $y \in C$, let $y_{t}=t y+(1-t) z$. Since $y \in C$ and $z \in C$, we have $y_{t} \in C$ and hence $f\left(y_{t}, z\right) \leq 0$. So, from the convexity of the equilibrium bifunction $f(x, y)$ on the second variable $y$, we have

$$
0=f\left(y_{t}, y_{t}\right) \leq t f\left(y_{t}, y\right)+(1-t) f\left(y_{t}, z\right) \leq t f\left(y_{t}, y\right),
$$

and hence $f\left(y_{t}, y\right) \geq 0$. Now, letting $t \rightarrow 0$ and condition (A3), we obtain that $f(z, y) \geq 0$, for all $y \in C$, and hence $z \in E P(f)$.

Next, we show that $z \in \cap_{i=1}^{N} F\left(T_{i}\right)$. But, since each $T_{i}$ satisfies condition (B3) we obtain from (3.13) and (3.15) that $z \in F\left(T_{i}\right)$, for each $i=1,2, \ldots, N$, and hence $z \in \cap_{i=1}^{N} F\left(T_{i}\right)$. Thus, from the above discussions we obtain that $z \in F:=\cap_{i=1}^{N} F\left(T_{i}\right) \cap E P(f)$. Therefore, by Lemma 2.3, we immediately obtain that $\lim \sup _{n \rightarrow \infty}\left\langle z_{n}-x^{*}, J w-J x^{*}\right\rangle=\lim _{i \rightarrow \infty}\left\langle z_{n_{i}}-\right.$ $\left.x^{*}, J w-J x^{*}\right\rangle=\left\langle z-x^{*}, J w-J x^{*}\right\rangle \leq 0$. It follows from (3.8) and Lemma 2.9 that $\phi\left(x^{*}, x_{n}\right) \rightarrow 0$, as $n \rightarrow \infty$. Consequently, $x_{n} \rightarrow x^{*}$ by Lemma 2.5. 
Case 2. Suppose that there exists a subsequence $\left\{n_{i}\right\}$ of $\{n\}$ such that

$$
\phi\left(x^{*}, x_{n_{i}}\right)<\phi\left(x^{*}, x_{n_{i}+1}\right)
$$

for all $i \in \mathbb{N}$. Then, by Lemma 2.8, there exist a nondecreasing sequence $\left\{m_{k}\right\} \subset \mathbb{N}$ such that $m_{k} \rightarrow \infty, \phi\left(x^{*}, x_{m_{k}}\right) \leq \phi\left(x^{*}, x_{m_{k}+1}\right)$ and $\phi\left(x^{*}, x_{k}\right) \leq \phi\left(x^{*}, x_{m_{k}+1}\right)$, for all $k \in \mathbb{N}$. Now, from (3.7) and the fact that $\delta_{n} \rightarrow 0$, we have

$$
\begin{aligned}
& \beta_{m_{k}, 0} \phi\left(x_{m_{k}}, w_{m_{k}}\right)+\beta_{m_{k}, 0} \beta_{m_{k}, i} g\left(\left\|J w_{m_{k}}-J u_{m_{k}, i}\right\|\right) \\
& \leq\left(\phi\left(x^{*}, x_{m_{k}}\right)-\phi\left(x^{*}, x_{m_{k}+1}\right)\right)-\delta_{m_{k}} \phi\left(x^{*}, x_{m_{k}}\right)+2 \delta_{m_{k}}\left\langle z_{m_{k}}-x^{*}, J w-J x^{*}\right\rangle,
\end{aligned}
$$

as $k \rightarrow \infty$. Thus, using the same proof of Case 1 , we obtain that $x_{m_{k}}-w_{m_{k}} \rightarrow 0$ and $w_{m_{k}}-$ $u_{m_{k}, i} \rightarrow 0$, as $k \rightarrow \infty$, for each $i=1,2, \ldots, N$ and hence

$$
\limsup _{n \rightarrow \infty}\left\langle z_{m_{k}}-x^{*}, J w-J x^{*}\right\rangle \leq 0
$$

Then from (3.8), we have that

$$
\phi\left(x^{*}, x_{m_{k}+1}\right) \leq\left(1-\delta_{m_{k}}\right) \phi\left(x^{*}, x_{m_{k}}\right)+2 \delta_{m_{k}}\left\langle z_{m_{k}}-x^{*}, J w-J x^{*}\right\rangle .
$$

Since $\phi\left(x^{*}, x_{m_{k}}\right) \leq \phi\left(x^{*}, x_{m_{k}+1}\right),(3.21)$ implies that

$$
\begin{aligned}
\delta_{m_{k}} \phi\left(x^{*}, x_{m_{k}}\right) & \leq \phi\left(x^{*}, x_{m_{k}}\right)-\phi\left(x^{*}, x_{m_{k}+1}\right)+2 \delta_{m_{k}}\left\langle z_{m_{k}}-x^{*}, J w-J x^{*}\right\rangle \\
& \leq 2 \delta_{m_{k}}\left\langle z_{m_{k}}-x^{*}, J w-J x^{*}\right\rangle .
\end{aligned}
$$

In particular, since $\delta_{m_{k}}>0$, we get

$$
\phi\left(x^{*}, x_{m_{k}}\right) \leq 2\left\langle z_{m_{k}}-x^{*}, J w-J x^{*}\right\rangle .
$$

Then, from (3.20), we obtain that $\phi\left(x^{*}, x_{m_{k}}\right) \rightarrow 0$, as $k \rightarrow \infty$. This together with (3.21) gives $\phi\left(x^{*}, x_{m_{k}+1}\right) \rightarrow 0$, as $k \rightarrow \infty$. But $\phi\left(x^{*}, x_{k}\right) \leq \phi\left(x^{*}, x_{m_{k}+1}\right)$ for all $k \in \mathbb{N}$, thus we obtain that $x_{k} \rightarrow x^{*}$. Therefore, from the above two cases, we can conclude that $\left\{x_{n}\right\}$ converges strongly to $x^{*}$ and the proof is complete.

If in Theorem 3.1, we assume that $f(x, y)=\langle A x, y-x\rangle$, for $A$ continuous monotone mapping, then we obtain the following corollary.

Corollary 3.2. Let $C$ be a nonempty, closed and convex subset of a uniformly smooth and uniformly convex real Banach space E. Let $A: C \rightarrow E^{*}$ be a continuous monotone mapping. 
Let $T_{i}: C \rightarrow C B(C)$, for $i=1,2, \ldots, N$, be a finite family of relatively nonexpansive multi-valued mappings. Assume that $F:=\cap_{i=1}^{N} F\left(T_{i}\right) \cap V I(C, A)$ is nonempty. Let $\left\{x_{n}\right\}$ be a sequence generated by

$$
\begin{gathered}
x_{0}=w \in C, \quad \text { chosen arbitrarily, } \\
w_{n} \in C \quad \text { such that }\left\langle A w_{n}, y-w_{n}\right\rangle+\frac{1}{r_{n}}\left\langle y-w_{n}, J w_{n}-J x_{n}\right\rangle \geq 0, \quad \forall y \in C, \\
y_{n}=\Pi_{C} J^{-1}\left(\alpha_{n} J w+\left(1-\alpha_{n}\right) J w_{n}\right), \\
x_{n+1}=J^{-1}\left(\beta_{n, 0} J w_{n}+\sum_{i=1}^{N} \beta_{n, i} J u_{n, i}\right), \quad u_{n, i} \in T_{i} y_{n}, n \geq 0,
\end{gathered}
$$

where $\alpha_{n} \in(0,1)$ such that $\lim _{n \rightarrow \infty} \alpha_{n}=0, \sum_{n=1}^{\infty} \alpha_{n}=\infty,\left\{\beta_{n, i}\right\} \subset[a, b] \subset(0,1)$, for $i=1,2, \ldots, N$, satisfying $\beta_{n, 0}+\beta_{n, 1}+\cdots+\beta_{n, N}=1$, for each $n \geq 0$. Then $\left\{x_{n}\right\}$ converges strongly to an element of $F$.

Proof. Let $f(x, y)=\langle A x, y-x\rangle$. Since $A$ is monotone and continuous, we get that a bifunction $f$ satisfies conditions (A1)-(A4). Thus, the conclusion follows from Theorem 3.1.

If in Theorem 3.1, we assume that $N=1$, then we get the following theorem.

Corollary 3.3. Let $C$ be a nonempty, closed, and convex subset of a uniformly smooth and uniformly convex real Banach space $E$. Let $f: C \times C \rightarrow \mathbb{R}$, be a bifunction which satisfies conditions (A1)$(A 4)$. Let $T: C \rightarrow C B(C)$ be a relatively nonexpansive multi-valued mapping. Assume that $F:=$ $F(T) \cap E P(f)$ is nonempty. Let $\left\{x_{n}\right\}$ be a sequence generated by

$$
\begin{gathered}
x_{0}=w \in C, \quad \text { chosen arbitrarily, } \\
w_{n}=F_{r_{n}} x_{n}, \\
y_{n}=\Pi_{C} J^{-1}\left(\alpha_{n} J w+\left(1-\alpha_{n}\right) J w_{n}\right), \\
x_{n+1}=J^{-1}\left(\beta_{n} J w_{n}+\left(1-\beta_{n}\right) J u_{n}\right), \quad u_{n} \in T y_{n}, n \geq 0,
\end{gathered}
$$

where $\alpha_{n} \in(0,1)$ such that $\lim _{n \rightarrow \infty} \alpha_{n}=0, \sum_{n=1}^{\infty} \alpha_{n}=\infty,\left\{\beta_{n}\right\} \subset[a, b] \subset(0,1)$, for each $n \geq 0$. Then $\left\{x_{n}\right\}$ converges strongly to an element of $F$.

Proof. The proof follows from Theorem 3.1 with $N=1$.

If in Theorem 3.1, we assume that $f \equiv 0$, we get the following corollary.

Corollary 3.4. Let $C$ be a nonempty, closed and convex subset of a uniformly smooth and uniformly convex real Banach space $E$. Let $T_{i}: C \rightarrow C B(C)$, for $i=1,2, \ldots, N$, be a finite family of relatively 
nonexpansive multi-valued mappings. Assume that $F:=\cap_{i=1}^{N} F\left(T_{i}\right)$ is nonempty. Let $\left\{x_{n}\right\}$ be a sequence generated by

$$
\begin{gathered}
x_{0}=w \in C, \quad \text { chosen arbitrarily, } \\
y_{n}=\Pi_{C} J^{-1}\left(\alpha_{n} J w+\left(1-\alpha_{n}\right) J x_{n}\right), \\
x_{n+1}=J^{-1}\left(\beta_{n, 0} J x_{n}+\sum_{i=1}^{N} \beta_{n, i} J u_{n, i}\right), \quad u_{n, i} \in T_{i} y_{n}, n \geq 0,
\end{gathered}
$$

where $\alpha_{n} \in(0,1)$ such that $\lim _{n \rightarrow \infty} \alpha_{n}=0, \sum_{n=1}^{\infty} \alpha_{n}=\infty,\left\{\beta_{n, i}\right\} \subset[a, b] \subset(0,1)$, for $i=1,2, \ldots, N$ satisfying $\beta_{n, 0}+\beta_{n, 1}+\cdots+\beta_{n, N}=1$, for each $n \geq 0$. Then $\left\{x_{n}\right\}$ converges strongly to an element of $F$.

If in Theorem 3.1, we assume that each $T_{i}, i=1,2, \ldots, N$ is single valued, we get the following corollary.

Corollary 3.5. Let $C$ be a nonempty, closed and convex subset of a uniformly smooth and uniformly convex real Banach space $E$. Let $f: C \times C \rightarrow \mathbb{R}$, be a bifunction which satisfies conditions (A1)(A4). Let $T_{i}: C \rightarrow C$, for $i=1,2, \ldots, N$, be a finite family of relatively nonexpansive single-valued mappings. Assume that $F:=\cap_{i=1}^{N} F\left(T_{i}\right) \cap E P(f)$ is nonempty. Let $\left\{x_{n}\right\}$ be a sequence generated by

$$
\begin{gathered}
x_{0}=w \in C, \quad \text { chosen arbitrarily, } \\
w_{n}=F_{r_{n}} x_{n}, \\
y_{n}=\Pi_{C} J^{-1}\left(\alpha_{n} J w+\left(1-\alpha_{n}\right) J w_{n}\right), \\
x_{n+1}=J^{-1}\left(\beta_{n, 0} J w_{n}+\sum_{i=1}^{N} \beta_{n, i} J T_{i} y_{n}\right), \quad n \geq 0,
\end{gathered}
$$

where $\alpha_{n} \in(0,1)$ such that $\lim _{n \rightarrow \infty} \alpha_{n}=0, \sum_{n=1}^{\infty} \alpha_{n}=\infty,\left\{\beta_{n, i}\right\} \subset[a, b] \subset(0,1)$, for $i=1,2, \ldots, N$, satisfying $\beta_{n, 0}+\beta_{n, 1}+\cdots+\beta_{n, N}=1$, for each $n \geq 0$. Then $\left\{x_{n}\right\}$ converges strongly to an element of $F$.

If $E=H$, a real Hilbert space, then $E$ is uniformly convex and uniformly smooth real Banach space. In this case, $J=I$, identity map on $H$ and $\Pi_{C}=P_{C}$, projection mapping from $H$ onto $C$. Thus, the following corollary holds.

Corollary 3.6. Let $C$ be a nonempty, closed, and convex subset of a Hilbert space $H$. Let $f: C \times C \rightarrow$ $\mathbb{R}$, be a bifunction which satisfies conditions (A1)-(A4). Let $T_{i}: C \rightarrow C B(C)$, for $i=1,2, \ldots, N$, be 
a finite family of relatively nonexpansive multi-valued mappings. Assume that $F:=\cap_{i=1}^{N} F\left(T_{i}\right) \cap E P(f)$ is nonempty. Let $\left\{x_{n}\right\}$ be a sequence generated by

$$
\begin{gathered}
x_{0}=w \in C, \quad \text { chosen arbitrarily, } \\
w_{n}=F_{r_{n}} x_{n}, \\
y_{n}=P_{C}\left(\alpha_{n} w+\left(1-\alpha_{n}\right) w_{n}\right), \\
x_{n+1}=\beta_{n, 0} w_{n}+\sum_{i=1}^{N} \beta_{n, i} u_{n, i}, \quad u_{n, i} \in T_{i} y_{n}, n \geq 0,
\end{gathered}
$$

where $\alpha_{n} \in(0,1)$ such that $\lim _{n \rightarrow \infty} \alpha_{n}=0, \sum_{n=1}^{\infty} \alpha_{n}=\infty,\left\{\beta_{n, i}\right\} \subset[a, b] \subset(0,1)$, for $i=1,2, \ldots, N$, satisfying $\beta_{n, 0}+\beta_{n, 1}+\cdots+\beta_{n, N}=1$, for each $n \geq 0$. Then $\left\{x_{n}\right\}$ converges strongly to an element of $F$.

Remark 3.7. (1) Theorem 3.1 improves and extends the corresponding results of Kumanm [22] and Takahashi and Zembayashi [16] in the sense that either our scheme does not require computation of $C_{n+1}$, for each $n \geq 1$, or the space considered is more general.

(2) Theorem 3.1 improves the corresponding results of Homaeipour and Razani [3] in the sense that our convergence is strong and the requirement that the interior of $F$ is nonempty is dispensed with.

\section{Acknowledgment}

The authors thank the reviewers for their useful comments.

\section{References}

[1] Y. I. Alber, "Metric and generalized projection operators in Banach spaces: properties and applications," in Theory and Applications of Nonlinear Operators of Accretive and Monotone Type, A. G. Kartsatos, Ed., vol. 178 of Lecture Notes in Pure and Applied Mathematics, pp. 15-50, Dekker, New York, NY, USA, 1996.

[2] S. Reich, "A weak convergence theorem for the alternating method with Bregman distances," in Theory and Applications of Nonlinear Operators of Accretive and Monotone Type, A. G. Kartsatos, Ed., vol. 178 of Lecture Notes in Pure and Applied Mathematics, pp. 313-318, Dekker, New York, NY, USA, 1996.

[3] S. Homaeipour and A. Razani, "Weak and strong convergence theorems for relatively nonexpansive multi-valued mappings in Banach spaces," Fixed Point Theory and Applications, vol. 2011, article 73, 2011.

[4] J. T. Markin, "Continuous dependence of fixed point sets," Proceedings of the American Mathematical Society, vol. 38, pp. 545-547, 1973.

[5] S. B. Nadler, "Multi-valued contraction mappings," Pacific Journal of Mathematics, vol. 30, pp. 475-488, 1969.

[6] L. Górniewicz, Topological Fixed Point Theory of Multivalued Mappings, vol. 495 of Mathematics and Its Applications, Kluwer Academic, Dordrecht, The Netherlands, 1999.

[7] T. C. Lim, "A fixed point theorem for multivalued nonexpansive mappings in a uniformly convex Banach space," Bulletin of the American Mathematical Society, vol. 80, pp. 1123-1126, 1974.

[8] W. R. Mann, "Mean value methods in iteration," Proceedings of the American Mathematical Society, vol. 4, pp. 506-510, 1953.

[9] Y. Haugazeau, Sur les inequations variationnelles et la minimisation de fonctionnelles convexes [These], Universite de Paris, Paris, France, 1967.

[10] H. H. Bauschke and P. L. Combettes, "A weak-to-strong convergence principle for Fejér-monotone methods in Hilbert spaces," Mathematics of Operations Research, vol. 26, no. 2, pp. 248-264, 2001. 
[11] S.-Y. Matsushita and W. Takahashi, "A strong convergence theorem for relatively nonexpansive mappings in a Banach space," Journal of Approximation Theory, vol. 134, no. 2, pp. 257-266, 2005.

[12] K. Nakajo and W. Takahashi, "Strong convergence theorems for nonexpansive mappings and nonexpansive semigroups," Journal of Mathematical Analysis and Applications, vol. 279, no. 2, pp. 372 379, 2003.

[13] S. Dhompongsa, W. Takahashi, and H. Yingtaweesittikul, "Weak convergence theorems for equilibrium problems with nonlinear operators in Hilbert spaces," Fixed Point Theory, vol. 12, no. 2, pp. 309-320, 2011.

[14] X. Qin, Y. J. Cho, and S. M. Kang, "Convergence theorems of common elements for equilibrium problems and fixed point problems in Banach spaces," Journal of Computational and Applied Mathematics, vol. 225, no. 1, pp. 20-30, 2009.

[15] Y. Su and X. Qin, "Monotone CQ iteration processes for nonexpansive semigroups and maximal monotone operators," Nonlinear Analysis, vol. 68, no. 12, pp. 3657-3664, 2008.

[16] W. Takahashi and K. Zembayashi, "Strong and weak convergence theorems for equilibrium problems and relatively nonexpansive mappings in Banach spaces," Nonlinear Analysis, vol. 70, no. 1, pp. 45-57, 2009.

[17] P. Yang and Y. Yao, "On modified iterative method for generalized equilibrium problems and fixed point problems," Journal of Advanced Mathematical Studies, vol. 4, no. 2, pp. 97-108, 2011.

[18] H. Zegeye and N. Shahzad, "Strong convergence theorems for monotone mappings and relatively weak nonexpansive mappings," Nonlinear Analysis, vol. 70, no. 7, pp. 2707-2716, 2009.

[19] H. Zegeye and N. Shahzad, "Approximating common solution of variational inequality problems for two monotone mappings in Banach spaces," Optimization Letters, vol. 5, no. 4, pp. 691-704, 2011.

[20] H. Zegeye and N. Shahzad, "A hybrid scheme for finite families of equilibrium, variational inequality and fixed point problems," Nonlinear Analysis, vol. 74, no. 1, pp. 263-272, 2011.

[21] H. Zegeye and N. Shahzad, "A hybrid approximation method for equilibrium, variational inequality and fixed point problems," Nonlinear Analysis: Hybrid Systems, vol. 4, no. 4, pp. 619-630, 2010.

[22] P. Kumam, "A hybrid approximation method for equilibrium and fixed point problems for a monotone mapping and a nonexpansive mapping," Nonlinear Analysis, vol. 2, no. 4, pp. 1245-1255, 2008.

[23] H. Zegeye, E. U. Ofoedu, and N. Shahzad, "Convergence theorems for equilibrium problem, variational inequality problem and countably infinite relatively quasi-nonexpansive mappings," Applied Mathematics and Computation, vol. 216, no. 12, pp. 3439-3449, 2010.

[24] S. Kamimura and W. Takahashi, "Strong convergence of a proximal-type algorithm in a Banach space," SIAM Journal on Optimization, vol. 13, no. 3, pp. 938-945, 2002.

[25] P. E. Maingé, "Strong convergence of projected subgradient methods for nonsmooth and nonstrictly convex minimization," Set-Valued Analysis, vol. 16, no. 7-8, pp. 899-912, 2008.

[26] J. G. O'Hara, P. Pillay, and H. K. Xu, “Iterative approaches to convex feasibility problems in Banach spaces," Nonlinear Analysis, vol. 64, no. 9, pp. 2022-2042, 2006. 


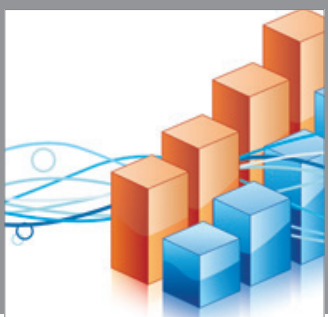

Advances in

Operations Research

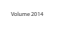

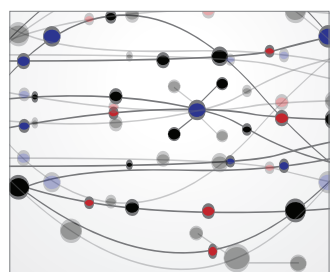

\section{The Scientific} World Journal
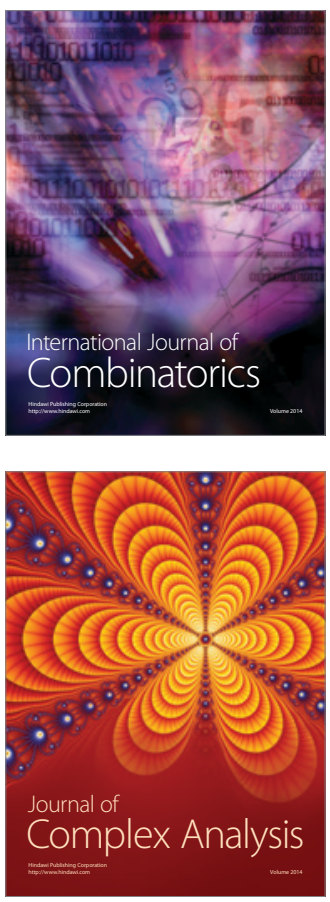

International Journal of

Mathematics and

Mathematical

Sciences
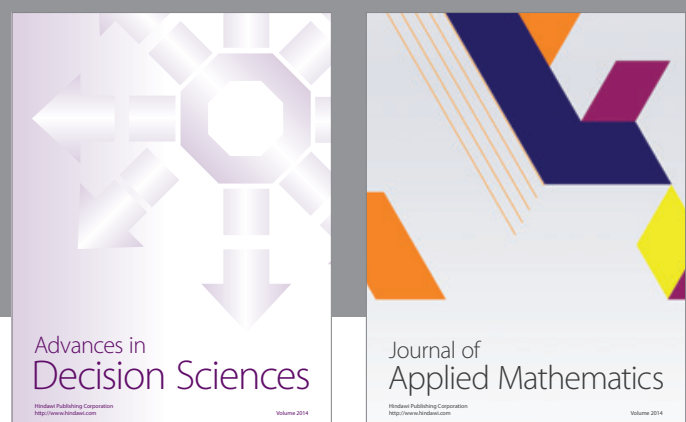

Journal of

Applied Mathematics
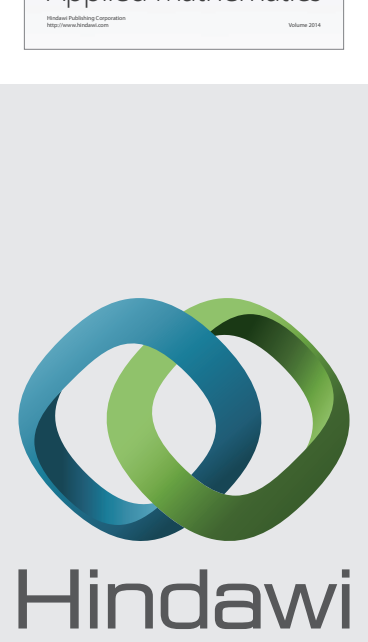

Submit your manuscripts at http://www.hindawi.com
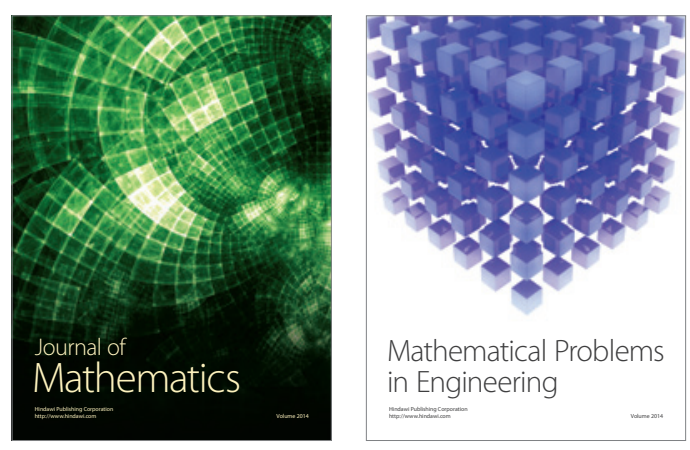

Mathematical Problems in Engineering
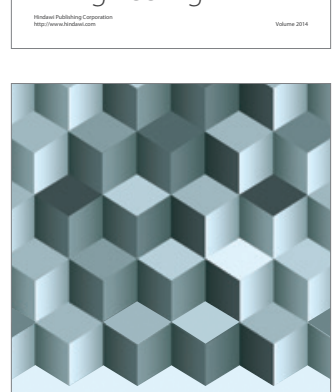

Journal of

Function Spaces
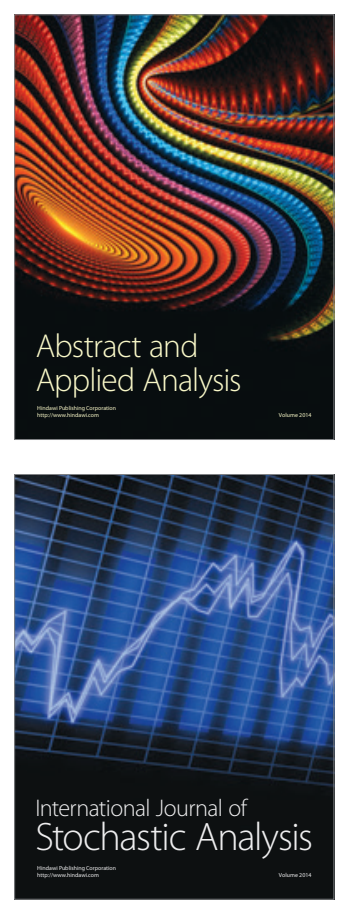

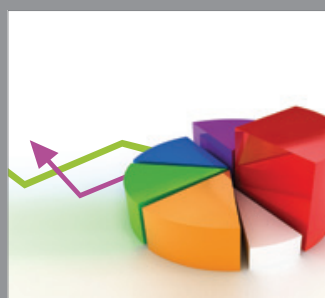

ournal of

Probability and Statistics

Promensencen
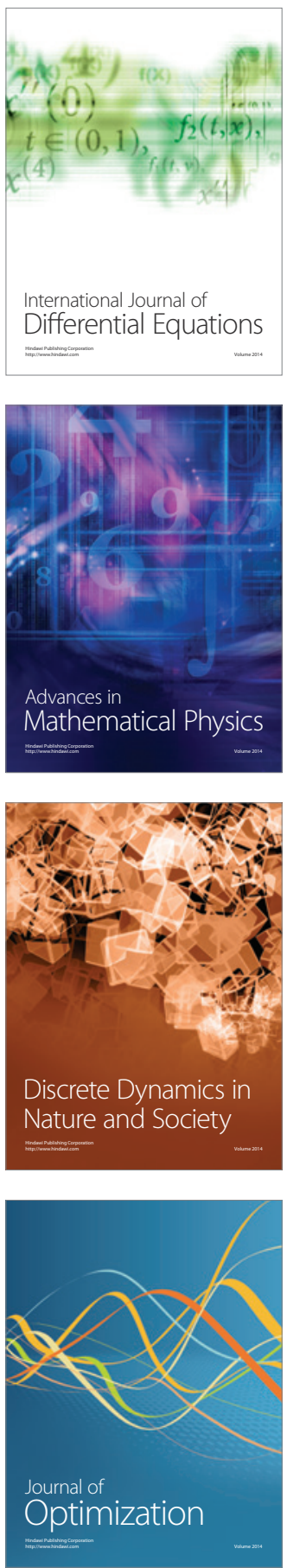